\title{
Performance e Educação: configurações parateatrais da docência
}

Performance and Education: paratheatrilized settings of teaching

Marcelo de Andrade Pereira*

Universidade Federal de Santa Maria

Resumo Este texto procura discutir a docência como performance parateatral. Para tanto, parte-se da contribuição dos Estudos da Performance e das discussões contemporâneas da Educação, introduzindo conceitos como cotidiano, performatividade, prática docente. Problematiza-se a natureza e a função do ato docente em sua teatralidade. As figuras do clown, do bufão e do dândi são convocadas para servirem de apoio por intermédio do qual a performance e a teatralidade do ato docente encontram termo.

PALAVRAS-CHAVE: Docência, performance, teatro.

Abstract This paper discusses teaching as paratheatrical performance. To reach this aim, we rely on Performance Studies and contemporary discussions of Education, introducing concepts such as everyday life, performativity, and the teaching practice. The text problematizes the nature and function of teaching in its theatricality. The figures of the clown, the jester or the dandy are brought in as a support through which the performance and theatricality of the act of teaching are carried out.

KEYWORDS: Teaching, performance, theatre. 
Desde que Nicolas Evreinoff (1930) teorizou sobre a mise en scéne da vida cotidiana, um amplo espectro de possibilidades se abriu para pensar os comportamentos humanos como dotados de características teatrais. Para evitar o etnocentrismo que o termo "teatral" implica e para ampliar as possibilidades de pesquisa nesta área, paulatinamente, o termo performance foi tomando lugar para dar visibilidade ao comportamento cotidiano como performance, tal como nos diria Richard Schechner (2002), pioneiro do que se convencionou chamar Estudos da Performance ou Teoria da Performance.

É nesse caminho que este texto propõe pensar a docência como performance, como um modo específico de desempenhar um papel social que supõe determinadas regras e discursos, pois "ensinar não constitui uma performance artística, mas certamente é uma performance. No ensinar, o professor precisa definir certas relações com os estudantes. $\mathrm{O}$ professor precisa desempenhar o papel do professor, que pode variar de circunstância a circunstância" (SCHECHNER, 2010, p. 30)

Num primeiro momento, o professor não desempenha uma ação de todo autoconsciente, o que conformaria a arte da performance, tal como no teatro, na dança, nos espetáculos em geral; mas há, provavelmente, um tipo de atuação que parece provocar os efeitos próprios de uma performance. Tais efeitos permitem vislumbrar configurações parateatrais na ação docente, pois o caráter teatral dessa atuação confere a ela uma lente de aumento ficcional para questões do cotidiano, da realidade da sala de aula - e também da realidade externa a ela.

Não surpreende, portanto, como infere Marvin Carlson, que a performance tenha se tornado sobremaneira visível no mundo contemporâneo

[...] um mundo que é altamente autoconsciente, reflexivo, obcecado com simulações e teatralizações em cada aspecto de sua sensibilização social. Com a performance como um tipo de plataforma crítica, a metáfora da teatralidade saiu das artes em quase todos os aspectos das tentativas modernas de entender nossa condição e atividades, em quase todos os ramos das ciências humanas - sociologia, antropologia, etnografia, psicologia, lingüística. E como a performatividade e a teatralidade tem se desenvolvido nesses campos, ambos como metáforas e como ferramentas de análise, teóricos e praticantes da performance art tem, por sua vez, tomado conhecimento dessa evolução e achado em si próprios novas fontes de estimulação, inspiração e insight para o seu próprio trabalho criativo e o entendimento teórico dele. (CARLSON, 2013, p. 6)

Não obstante, vale recobrar as contribuições de Aristóteles (1969) para quem a representação teatral - e porque não dizer, a performatividade - cooperaria para uma melhor apreensão dos problemas que afligem ou que atravessam uma determinada sociedade. Tratar-se-ia, com efeito, de tornar ou evidenciar os problemas sob diferentes pontos de vista, poderíamos chamar isso de uma tomada de consciência das habilidades e dos fazeres cotidianos, não como uma simples luz sobre algo já dado, mas como um processo de criação de novidades por intermédio do jogo ficcional que a teatralidade propõe. 
Charles Garoian extrairá da arte da performance as qualidades dessa forma de expressão que julga adequada para sua proposta pedagógica, quais sejam: multicêntrica, paradoxal, participativa, indeterminada, interdisciplinar, reflexiva, intercultural, lúdica, estética, processual (GAROIAN, 1999, p. 47-48). A associação da pedagogia com a performance é, nesse sentido, auto-evidente. Isto porque, como sendo prática de crítica cultural, a performance interroga, resiste e intervém; designa uma forma liberadora de ação; dissolve as fronteiras entre a arte e a vida; rememora e reflete o vivido; relacionando-se, portanto, com o múltiplo, com o diverso e com o diferente.

Ao reconhecer a performance como expressão incorporada da cultura, Charles Garoian - nitidamente apoiado pelos postulados de Richard Schechner, em especial, no que concerne às qualidades da performance - antevê uma pedagogia radical, de intervenção, orientada por um discurso educacional que busca reposicionar as identidades culturais (condensadas no corpo) de professores e estudantes (GAROIAN, 1999, p. 37). Essa concepção pedagógica de performance não se distancia muito da concepção anteriormente descrita de Peter McLaren (1993), para quem a performance constitui uma "arena de ativismo cultural", a qual envolve "novos modos de representação".

Como em qualquer modo de representação social, existe já uma expectativa em relação ao que podemos esperar da performance do professor, dentro, evidentemente, de determinadas margens com as quais aceitamos, ou não, o que é e o que não é atuar como professor e como aluno. Não há, entre nós, contudo, nenhum estudo que se ocupe de formas de agir docente que se aproximam do agir teatral.

Este texto propõe, assim, segundo essa perspectiva, apresentar algumas figuras por intermédio das quais podemos pensar a tarefa de ensinar como performances atravessadas pelas características de tais figuras/personagens. Trata-se de discutir a pertinência de três figuras performativas potentes para a docência: o bufão, o clown e o dândi.

Não se trata, entretanto, de colar tais figuras ao comportamento do professor, tampouco de uma espécie de tipologia da prática docente. Ao contrário, tais figuras funcionariam como um mote para pensar a (para)teatralidade da ação docente a partir de uma concepção de teatro muito mais aproximada das artes performativas, portanto, mais afastada da ideia clássica de personagem, segundo a qual se trataria de uma ficção literária a ser interpretada por um ator. Tal qual as artes de performance, essas figuras constituem motes de ação e circunscrevem espaços de atuação nos quais o próprio performer é o centro da atuação. Isso não implica, portanto, a interpretação de um personagem, mas, fazendo o caminho contrário, reconhecer, em si, características que se aproximam dessas figuras na potencialidade de sua reflexão.

\section{A figura do bufão}

A figura do bufão não é, como nos lembra Icle e Lulkin (2013), propriamente moderna, mas pré-moderna; ela surge, historicamente, durante o Medievo, assumindo no contexto dessa época uma importância crucial mais do ponto de vista 
político que propriamente artístico. Na idade média, o Bufão não era exatamente um personagem no sentido que essa palavra vai assumir a partir do Renascimento e, principalmente, na consolidação da modernidade teatral do século XVIII em diante. No medievo, os bufões eram verdadeiramente indivíduos que usavam algum tipo de deformidade física ou mental para performatizar e dar-se a ver em apresentações públicas.

Essa tradição vinha desde a Antiguidade, seja nas cortes, nas quais os bobos eram autorizados a divertir reis e imperadores, seja nos ambientes populares, nos quais trupes de párias sociais apresentavam diferentes habilidades dramáticas ou parateatrais para sobreviver. Não se tratava, contudo, de espetáculos tais quais nos acostumamos a ver nas nossas sociedades pós-industriais, mas práticas performativas que envolviam uma autoridade em falar. Em muitos casos era pela performance do bobo, do bufão que a palavra interdita era possível. O bobo podia falar do rei ao rei e criticá-lo, ainda que, em alguns casos, sofressem as consequências. O bobo é, por assim dizer, o alterego do rei.

Assim, havia no bufão uma atividade de diversão e, ao mesmo tempo, de transgressão, tratava-se de divertir e divergir, de apresentar e criticar.

Ao contrário de outras atividades performáticas, o bufão fazia isso por intermédio de uma característica que lhe era particularmente peculiar, o grotesco. Nele, nas suas deformações, na sua impossibilidade de aceitação plena pela comunidade, residia a potência de uma intervenção do feio, do deformado, do obscuro, na qual se fazia sentir laivos de resistência.

Tais transgressões se davam por inúmeras habilidades, mas, principalmente, pela alegoria da inversão. O bufão no seu jogo cênico e performático podia parodiar, gozar, imitar qualquer figura importante, qualquer fato histórico, qualquer acontecimento cotidiano. $\mathrm{O}$ caráter grotesco da sua atuação funcionava, com efeito, tanto como máscara por intermédio da qual ele ficava protegido para falar, quanto efeito segundo o qual falar tomava um caráter cômico, visto a estranheza que a deformidade comportava.

Mesmo autorizado a falar nesse lócus específico, a cena, o bufão nunca deixou de ser um excluído, seja pela sua não conformidade física, seja pela sua falta de caráter civilizatório. Sendo assim, um bufão não pode ser concebido senão em bando, em grupo, na segurança de uma comunidade de bufões. O grupo é característica do bufão, portanto, ao invés de falar em bufão como indivíduo, seria melhor lembrar a bufonaria como conjunto, como ensemble, como coletivo que impede uma singularidade ao bufão, na medida em que o protege no conforto de um grupo que corresponde tanto à segurança, quanto ao olhar crítico.

Numa apropriação deveras consistente, Icle e Lulkin (2013) tomam a figura do bufão como um dispositivo didático. Dito de outro modo, os autores procuram pensar a figura do bufão como médium de reflexão para uma didática performatizada, "valendo-se da derrisão e da multiplicidade de sentidos que a bufonaria implica" (ICLE; LULKIN, 2013, p. 117); personagem que oscilaria, segundo os mesmos, entre a divergência e a diversão. A pragmática do riso, embutida nessa concepção bufônica 
de pedagogia, visa sustentar uma forma de agir docente que levaria os sujeitos da educação ao limite do pensamento e da razão. Tal atitude seria uma contrapartida à desolação e ao "desconforto com a banalização do trágico e à mediocrização do cômico em nosso cotidiano e como isso é perceptível nos discursos da disciplina e da violência presentes nos espaços escolares" (ICLE; LULKIN, 2013, p. 118).

Um outro aspecto de fundamental importância ao se pensar a bufonaria como forma didática diz respeito à intervenção no corpo no conjunto da materialidade de tal discurso pedagógico. A pragmática do riso, referida por Icle e Lulkin (2013), toma o humor numa dupla acepção, ora como comicidade, ora como corporeidade. $\mathrm{O}$ riso provoca não apenas o pensamento, mas, de igual modo, uma resposta visceral, corporal a estímulos de tal natureza. O sentido depreendido dessa prática remontaria, assim, mais à um campo não hermenêutico que propriamente hermenêutico. $\mathrm{O}$ sentido da ação, dito de outro modo, reverbera num registro muito mais profundo que o cognitivo, que borra inclusive os limites constituídos dentro desse esquema, ampliando-os, corporficando-os. Trata-se de um campo de experimentação ético-estética, que extrapola o discursivo, o que pode ser interpretado, abrindo espaço para a dúvida e o reconhecimento de outras formas de ser, da alteridade propriamente dita.

Se o personagem conceitual do bufão nos possibilita pensar performaticamente a didática é porque ele supõe a centralidade do corpo como locus da experiência, como lugar de um ato que se passa e nos passa no aqui - agora. A esse ato nomeamos, juntamente com Gumbrecht (2004), de presença. Mas além de recolocar a didática no corpo, a performance do bufão nos lembra que a presença qualitativa que envolve a performance é sempre uma experiência compartilhada, um jogo de relação com a alteridade, nunca uma prática individual. Ela envolve sempre as dimensões do atuante e do public. (ICLE; LULKIN, 2013, p. 125)

\section{A figura do clown}

O clown, diferentemente do bufão, se ocupa da dimensão inocente da comicidade. Trata-se de um misto de inocência e comoção. O clown se aproxima assim de uma crítica mais humana, de evidenciar uma condição absurda da humanidade: existir. Ele o faz por intermédio da gag, pequena sequência de ações com laivos obsessivos, na qual o clown procura resolver um problema simples do cotidiano, segundo uma lógica absurda.

Historicamente, o clown tomou existência no circo criado na Europa do século XVIII. Antes disso, seus ancestrais, bufões, bobos, palhaços, artistas do corpo, da Antiguidade à Commedia Dell'Arte, experimentavam o nonsense alternado com o grotesco. Mas a constituição do circo moderno trouxe a possibilidade de uma ribalta definitiva para essa figura, circunscrevendo o picadeiro como espaço de excelência do clown. A rigor, o termo clown surge apenas durante o período elisabetano, quando a palavra adentra a linguagem para referir a noção de um indivíduo cuja rusticidade o torna inferior ou mesmo ridículo (WILES, 2005, p. 61). A palavra colono, deveras conhecida na região sul do Brasil, opera como sinônimo dessa acepção primária de 
clown. A correlação do clown com a rusticidade e, por conseguinte, com o colono, emerge, de acordo com Wiles (2005, p. 62), no centro do discurso cavalheiresco, como antítese do gentil, do acabado, do honroso, do superior, do sujeito pertencente à classe mais honrosa e valiosa.

De qualquer modo, o caráter introvertido, individual e cômico possibilitou, também, uma aproximação e uma presença forte como pode ser visto no cinema nascente da primeira metade do século XX.Como figura ambivalente, o clown constitui uma dimensão idiota e idiotizada do ser humano. Ele evidencia a condição cômica, a inocência e, sobretudo, a inconsciência da vida vivida no inconsciente do cotidiano repetitivo. Tratar-se-ia de uma inveterada ação inútil. O clown se ocupa de coisas pequenas, de tarefas ordinárias, de ordens dadas a ele por uma sociedade baseada na ordem. Entretanto, é desordem, é inocência infantil de um ser que não pretende representar nada, que não constitui um personagem - no sentido dado à literatura dramática ou não -, mas uma condição: todo somos clowns perdidos na nossa existência sem sentido.

A rigor, como observa acertadamente David Robb (2007), o caráter híbrido ou dinâmico do clown pode constituir uma contrapartida crítica às rígidas formas hegemônicas de ser em sociedade e/ou à dogmas ideológicos, como também uma forma de projetar as ilusões, anseios ou utopias reprimidas de uma dada sociedade. Isso explica porque para Robb o clown habita um mundo fronteiriço, oscilando entre “a estrutura e a não estrutura, a realidade e o sonho, a tragédia e a comédia, a razão e a loucura" (ROBB, 2007, p. 1).

Seja como for, o circo moderno, sobretudo a partir do século XIX, imortalizou dois tipos clássicos de clowns: o branco e o augusto. O primeiro é o clown seguro, certo de si e dono de um ar, não raro arrogante, superior. Ele pensa que não é idiota, mas sua ação mostra sua profunda ignorância e sua limitação ainda mais evidente do que o augusto. Este último, por sua vez, é o idiota completo que só pode encontrar razão no acaso, na saída tangencial e inesperada ocasionada pela inocência completa.

No cinema a dupla o Gordo e o Magro são um exemplo dessa tipologia: o Gordo sendo um clown branco, enquanto o Magro, o augusto. Nessa relação de par clown branco clown augusto - circunscreve-se a existência dessa figura, uma relação de existência dada pela intervenção da tarefa, com resultado cômico. $\mathrm{O}$ clown augusto pode, por ele mesmo, ao enfrentar as situações brancas, existir sozinho, bastaria lembrar mais uma vez o exemplo do cinema: Carlitos de Charles Chaplin.

Entrementes, pode-se afirmar que o cômico do clown é efeito de um sentido constituído na identificação - tal como anteriormente mencionada por David Robb (2007). Identificamos-nos com as mazelas dessa condição pequena e infantil. Vemos-nos retratados na nossa pequenez, na nossa insignificância, na nossa estupidez. O clown é o retrato de um homem perdido, mas que pode se reconhecer na sua complexa e difícil existência.

Vale assinalar, contudo, que a acepção de clown aqui apresentada configura apenas uma dentre muitas possíveis. A figura genérica do clown comporta uma vasta variedade, como também, diferenciações, tais como piadistas, mímicos, palhaços de 
circo, bobos e mesmo bufões. Seja como for, para todas essas distintas formas de nomeação, clown geralmente refere aquele que induz ao riso, qualidade essa presumida como axiomática (JANIK, 1998; OTTO, 2007; WILES, 2005). Todavia, em conformidade com Ashley Tobias, essa figura comunica algo para além da mera liberação do riso, tal como intuído anteriormente, o clown constitui uma figura altamente poética, reflexiva, cuja performance não se restringe necessariamente ao "engraçado", de modo a permitir uma fruição mais aprofundada e uma contemplação significativa (TOBIAS, 2007, p. 37).

\section{A figura do dândi}

O dândi, por sua vez, designa o sujeito que toma a própria vida como uma obra de arte, ou seja, o seu modo de se dar a ver apresenta uma suposta superioridade cultural expressa em gestos, vestuário, conversações. Trata-se de uma figura da metrópole, emergente na Inglaterra na virada do século XIX para o século XX.

Caracteriza-se, principalmente, pela super afetação e pela postura pró-aristocrática, em detrimento de uma postura burguesa. O seu vestuário marca o espírito de superioridade, de distância e distinção que são aclamados pelo dândi como um modo de ser. Fina ironia que expressa um modo de comportamento blasé e que considera qualquer vulgaridade um crime.

A extrema afetação busca sempre surpreender o olhar alheio, sem, contudo, jamais mostrar surpresa ele mesmo. Trata-se de um cultivo a bela aparência e um cultivo a retórica e aos costumes delicados. Retórica para o dândi é, sobretudo, um justo falar, uma adequação de tempo e espaço em relação ao falar. Evita-se, segundo ele, o franco falar ou o simples falar; mas valoriza-se a justeza e a adequação num falar que evita excessos.

O dândi não se ocupa de nada, para ele não há mundo do trabalho, mas na sua superficialidade aparente faz parecer que faz tudo como todos. Ele não faz nada como os outros, mas aparenta fazer tudo como os outros (BALZAC, 2009, p. 32). O sentimento que move o dândi é o de uma vida elegante, sóbria. Ele imprime o se tipo de pensamento sobre tudo o que o rodeia e o pertence. E é a partir da influência desse pensamento que a vida se enobrece, se aperfeiçoa e se engrandece (BAUDELAIRE, 2009, p. 45).

Trata-se de pensar uma figura que não vive sob a égide do tempo acelerado. "Ele alarga o tempo, pois a elegância dramatiza a vida [...]" (BALZAC, 2009, p. 52). Ele atenta a todas as nuances do tempo, de um tempo estendido, assim, "a vida elegante não exclui nem o pensamento, nem a ciência: ela os consagra. Ele não deve ensinar apenas a desfrutar do tempo, mas a utilizá-lo numa ordem extremamente elevada de ideias" (BALZAC, 2009, p. 82).

Somente na aparência o dândi é um irresponsável, um descomprometido com a vida social. De fato, ele faz um elogio da singularidade, ele torna nítido os signos de uma vida cultivada, de alta cultura. Trata-se, portanto, de um humor alegórico, irônico, refinado. $\mathrm{O}$ dândi trabalha na dimensão da ironia, ele aduz à comicidade pela 
palavra justa, pelo emprego, pelo uso da sofisticação, que não procura causar nenhum desconforto. Seu objetivo é sempre causar o conforto, pois ele porta uma palavra convencionada, o dândi, de fato, é o mestre da etiqueta, justamente porque ele sabe como isso pode funcionar como ação crítica.

\section{Reverberações na prática docente}

Eventualmente, como professores, personificamos bufões, clowns, dândis? Sabemos que o fazemos? Somos atravessados por tais alegorias? Antes de saber dizer com qual deles nos identificamos, seria mais produtivo perceber a potência dessa relação: performances docentes analisadas a partir de tais figuras. É provável que o componente crítico que o bufão, o clown e o dândi comportam constitui o elemento inevitável de ligação entre eles e a prática docente compreendida como performance.

Portanto, não se trata de fornecer instrumentos, mas um caminho compreendido como forma de entendimento de si e do mundo. Caminhos que poderiam afasta o indivíduos de paradigmas históricos e epistemológicos reprodutivos. A ideia de uma pedagogia performativa constitui a ideia de resistência. Portanto, analisar essas três figuras mostra a importante de sabermos como performamos nosso papel de professor e como a Escola performa os sujeitos, ritualizando algumas relações entre papéis performatizados.

Assim, ao tomar ciência da potência das configurações, a prática pedagógica tem a possibilidade de deixar de ser reprodutiva para ser produtiva, poética. Quando se fala, aqui, em poética, apresenta-se uma variável de ordem estética, a qual nos lança um espaço-tempo de presença e passível de experimentação.

Essas diferentes figurações da prática docente - o bufão, o clown, o dândi - aduzem a modos de olhar, de se comportar, de criticar, de dizer, e constituem possibilidades de escolha para o professor. Nisso, reside uma potencialidade, seja na acidez crítica do bufão, na ingenuidade infantil do clown, na impenetrabilidade elegante do dândi, seja na sua performatividade consciente.

Nessa arte da performance pedagógica, a consideração da dimensão estética constitui um imperativo educacional, visto que alude tanto às condições materiais de representação de uma dada subjetividade, quanto ao microcosmo de sentidos (dados e produzidos) instalado por meio do elemento estético. Essa afirmação encontra-se, como já se observou, no cerne da significação cultural da performance - tomada desde o ponto de vista das identificações e agenciamentos e dos respectivos modos de dar-se a ver (ou representar) no tecido social. Encontra-se, também, em relação à significação da performance como campo de trabalho artístico e cultural, heterogêneo, por intermédio do qual podem-se analisar os vários aspectos de produção dos comportamentos sociais (papéis e formas específicas de atuação), os quais são historicamente aprendidos e reproduzidos (GAROIAN, 1999, p. 8).

Assim, a performance do professor constitui uma forma de auto-consciência, não absoluta (GAROIAN, 1999, p. 10). Como tomada de consciência, a performance refere, também, um modo de posicionamento do indivíduo em meio à profusão 
de discursos que supostamente o sobredeterminariam. Parece, pois, evidente, que exista de maneira necessária, uma conexão entre a prática pedagógica e a produção artística. Para Garoian (1999, p. 3), o ensino pode conformar uma arte, assim como a arte pode, também, ensinar. Sob a forma de uma pedagogia artístico performativa, Garoian intui a exposição e a transformação de discursos culturais os mais diversos, não raro, conflituosos, dentro uma práxis social, o que permite, segundo ele, "criar novas idéias, imagens e ações baseadas na própria perspectiva cultural” (GAROIAN, 1999, p. 3).

É isso que as figurações deste texto pretendem: mostrar o intrincado espaço de criação que figuras tão distintas como o bufão, o clown, o dândi, podem aportar para a performance da prática docente.

Este trabalho procurou tornar saliente a liminaridade entre a performance - tomada desde sua interface com a teatralidade -, a vida cotidiana e a ação educativa, colocando em evidência formas de visibilidade em nossa sociedade que possuem distintas e performativas facetas. O objetivo deste trabalho foi, então, o de circunscrever a performance do professor como espaço de crítica e como metáfora para a reflexão; depreendendo da performance do professor seu caráter artístico e ritual; buscando, ainda, evidenciar o caráter parateatral da prática docente, a partir de diferentes configurações de professor que estabelecem atmosferas distintas e diferentes relações de ensino aprendizagem, seja favorecendo, seja comprometendo tais relações.

\section{Referências}

ARISTOTE. Poétique. Paris: Les Belles Lettres, 1969.

BALZAC, H. Tratado da vida elegante. In: BAUDELAIRE, C.; BALZAC, H.; D'AUREVILLY, B. Manual do dândi: a vida como estilo. Organização, tradução e notas Tomaz Tadeu. Belo Horizonte: Autêntica, 2009.

BAUDELAIRE, C.; BALZAC, H. de; D'AUREVILLY, B. Manual do dândi: a vida como estilo. Organização, tradução e notas Tomaz Tadeu. Belo Horizonte: Autêntica, 2009.

CARLSON, M. Performance: a critical introduction. New York: Routledge, 2013.

EVREINOFF, N. Le théâtre dans la vie. Paris: Librarie Stock, 1930.

GAROIAN, C. R. Performing pedagogy: toward an art of politics. New York: State University of New York Press, 1999.

ICLE, G.; LULKIN, S. Didática Buffa: uma crítica à interpretação numa performance da profanação. Currículo sem Fronteiras, v. 13, n. 2, p. 116-128, jan./abr. 2013.

JANIK, V. K. (Ed.). Fools and jesters in literature, art and history: a bio-bibliographical sourcebook. Westport: Greenwood Press, 1998.

OTTO, B. K. Fools are everywhere: the court jester around the world. Chicago: The University of Chicago Press, 2007.

ROBB, D. Introduction. In: ROBB, D. (Ed.) Clowns, Fools and Picaros: popular forms in Theatre, Fiction and Film. Amsterdam: Rodopi, 2007.

SCHECHNER, R.; ICLE, G.; PEREIRA, M. de A. O que pode a performance na educação? Uma entrevista com Richard Schechner. Educação \& Realidade, v. 2, n. 35, p. 23-35, maio/ ago. 2010. 
SCHECHNER, R. Performance studies: an introduction. London: Routledge, 2002.

TOBIAS, A. The post modern theatre clown. In: ROBB, D. (Ed.) Clowns, Fools and Picaros: popular forms in theatre, fiction and film. Amsterdam: Rodopi, 2007.

WILES, D. Shakespeare's Clown: actor and text in the elizabethan playhouse. Cambridge: Cambridge University Press, 2005.

* Professor Doutor da Universidade Federal de Santa Maria, Santa Maria, Rio Grande do Sul, Brasil.

Marcelo de Andrade Pereira - Av. Roraima, 1000. Campus Universitário - Centro de Educação, Departamento de Fundamentos da Educação, Camobi, CEP: 97105-900 - Santa Maria, Rio Grande do Sul - Brasil.

E-mail:doutorfungo@gmail.com

Recebido em 21 de março de 2014

Aprovado em 29 de julho de 2014 